\title{
B CHROMOSOMES AND MULTIVALENT FORMATION IN TETRAPLOID HYBRIDS BETWEEN BRIZA MEDIA AND BRIZA ELATIOR
}

\author{
B. G. MURRAY \\ Department of Botany and Biochemistry, Westfield College (University of London), \\ London NW3 7ST
}

Received 24.v.78

\section{SUMMARY}

In colchicine induced tetraploid hybrids between Briza media and Briza elatior, B chromosomes are shown to reduce homoeologous chromosome pairing. Large numbers of Bs have a considerably greater effect than small numbers on the frequency of multivalents and bivalents. A possible mechanism to explain the effects of B chromosomes on chromosome pairing in species hybrids is suggested which is related to the mechanism that prevents pairing between $A$ and $\mathbf{B}$ chromosomes.

\section{INTRODUGTION}

B CHromosomes have been shown to reduce homoeologous chromosome pairing at meiosis in a number of different diploid and tetraploid interspecific hybrids. However their effects are far from uniform and in hybrids between different pairs of species within a genus they may either have a drastic effect as in Lolium temulentum $\times$ Lolium perenne (Evans and Macefield, 1972, 1973 ) or a relatively mild one as in Lolium multiflorum $\times$ Lolium perenne (Evans and Macefield, 1974). In diploid hybrids between Briza media and Briza elatior there was a clear correlation between the number of B chromosomes and the degree of homoeologous pairing (Murray, 1976), the larger the number of $\mathbf{B}$ chromosomes the lower the chiasma frequency and bivalent frequency and the higher the frequency of univalents.

This paper describes the results obtained from a study of meiosis in colchicine induced tetraploid hybrids between $B$. media and $B$. elatior. It was undertaken to ascertain the effects, if any, of Bs on chromosome pairing at the tetraploid level in these hybrids.

\section{Materials AND METHODS}

The plants used in this study were derived from crosses between diploid individuals of $B$. media and $B$. elatior. The parental plants of $B$. media were collected as live plants from a natural population growing on Pilots Hill, Hampshire (grid ref. SU 406601), B. elatior plants were grown from seed obtained from Station Nationale d'essais de Semances, Versailles, France. In all cases the B chromosomes were derived from the elatior parent. The diploid plants reported on in an earlier publication (Murray, 1976) were of the same origin. Polyploids were produced by treating young seedlings with 0.1 per cent aqueous colchicine for four hours at room temperature. Surviving seedlings were transferred to pots and grown in the experimental garden until they flowered. For meiotic studies squash preparations of pollen mother cells (p.m.c.s) were made in aceto-orcein. 


\section{Results}

B chromosome number, chiasma frequency and the frequency of the various chromosome configurations were scored in 20 p.m.c.s per plant and the results are given in table 1 . These results show that in tetraploid hybrids

TABLE 1

Mean meiotic configurations in tetraploid hybrids between Briza media and Briza elatior with $0,2,4$, and $8 \mathrm{~B}$ chromosomes

\begin{tabular}{|c|c|c|c|c|c|c|}
\hline & I & II & III & IV & (Mult.) & Xta. freq. \\
\hline \multirow[t]{7}{*}{ OB Class } & 0.40 & $7 \cdot 70$ & $0 \cdot 20$ & $2 \cdot 90$ & $3 \cdot 10$ & 24.8 .5 \\
\hline & $1 \cdot 60$ & $10 \cdot 35$ & $0 \cdot 10$ & $1 \cdot 35$ & $1 \cdot 45$ & 22.75 \\
\hline & 1.75 & $8 \cdot 15$ & 0.55 & $2 \cdot 00$ & $2 \cdot 55$ & $21 \cdot 90$ \\
\hline & 0.70 & $5 \cdot 45$ & $0 \cdot 40$ & $3 \cdot 80$ & $4 \cdot 20$ & $23 \cdot 65$ \\
\hline & 1.50 & $7 \cdot 60$ & $0 \cdot 30$ & $2 \cdot 60$ & $2 \cdot 90$ & $23 \cdot 50$ \\
\hline & 0.50 & $9 \cdot 00$ & $0 \cdot 10$ & $2 \cdot 30$ & $2 \cdot 40$ & $25 \cdot 00$ \\
\hline & 0.36 & $8 \cdot 18$ & $0 \cdot 36$ & 2.55 & $2 \cdot 91$ & $24 \cdot 65^{1}$ \\
\hline mean & 0.97 & $8 \cdot 06$ & $0 \cdot 29$ & $2 \cdot 50$ & $2 \cdot 77$ & $23 \cdot 75$ \\
\hline \multirow[t]{3}{*}{ 2B Class } & $0 \cdot 35$ & 11.65 & 0.05 & 1.05 & $1 \cdot 10$ & $26 \cdot 50$ \\
\hline & $1 \cdot 00$ & $9 \cdot 35$ & $0 \cdot 30$ & $1 \cdot 85$ & $2 \cdot 15$ & $23 \cdot 30$ \\
\hline & 0.35 & $10 \cdot 05$ & $0 \cdot 25$ & $1 \cdot 70$ & 1.95 & $25 \cdot 80$ \\
\hline mean & 0.57 & $10 \cdot 35$ & $0 \cdot 20$ & 1.53 & $1 \cdot 80$ & $25 \cdot 20$ \\
\hline \multirow[t]{6}{*}{ 4B Class } & $0 \cdot 00$ & $12 \cdot 80$ & $0 \cdot 00$ & $0 \cdot 60$ & 0.60 & $27 \cdot 60$ \\
\hline & 0.70 & $11 \cdot 65$ & $0 \cdot 00$ & 0.75 & 0.75 & 24.90 \\
\hline & 0.00 & $12 \cdot 00$ & $0 \cdot 00$ & 1.00 & $1 \cdot 00$ & $27 \cdot 55$ \\
\hline & $0 \cdot 65$ & $12 \cdot 35$ & $0 \cdot 15$ & 0.55 & $0 \cdot 70$ & $24 \cdot 65$ \\
\hline & 0.45 & $9 \cdot 65$ & 0.15 & 1.95 & $2 \cdot 10$ & $25 \cdot 30$ \\
\hline & 0.00 & $12 \cdot 20$ & $0 \cdot 00$ & 0.90 & 0.90 & $26 \cdot 75$ \\
\hline mean & $0 \cdot 30$ & $11 \cdot 78$ & $0 \cdot 05$ & 0.96 & $1 \cdot 00$ & $26 \cdot 13$ \\
\hline \multirow[t]{4}{*}{ 8B Class } & 0.35 & $12 \cdot 65$ & 0.05 & 0.55 & $0 \cdot 60$ & $26 \cdot 55$ \\
\hline & 0.00 & $12 \cdot 80$ & $0 \cdot 00$ & $0 \cdot 60$ & $0 \cdot 60$ & $27 \cdot 65$ \\
\hline & $1 \cdot 55$ & $12 \cdot 40$ & 0.35 & $0 \cdot 15$ & $0 \cdot 50$ & $23 \cdot 50$ \\
\hline & 0.90 & $13 \cdot 00$ & $0 \cdot 10$ & $0 \cdot 20$ & $0 \cdot 30$ & 24.90 \\
\hline mean & 0.70 & $12 \cdot 71$ & $0 \cdot 13$ & 0.37 & 0.50 & $25 \cdot 65$ \\
\hline
\end{tabular}

between $B$. media and $B$. elatior different numbers of $B$ chromosomes have a very marked effect on chromosome pairing at meiosis. Within each $B$ chromosome class there is obviously a certain degree of variation between plants in the frequency of the different chromosome configurations but the regression of both multivalent and bivalent frequencies on $\mathrm{B}$ chromosome number is highly significant $(\mathrm{P}<0.01)$. In the absence of $\mathrm{B}$ chromosomes the meiotic behaviour of these hybrids is very similar to that of typical autotetraploids. There is a high degree of homoeologous pairing with the formation of many quadrivalents and few bivalents (fig. la and b). With increasing numbers of Bs the frequency of multivalents decreases and there is a corresponding increase in bivalent frequency (fig. lc, d, e, and f) until when eight Bs are present the frequency of bivalent formation is very high and very few multivalents are formed.

There is also a significant increase $(\mathrm{P}<0.05)$ in chiasma frequency with increasing numbers of $\mathrm{B}$ chromosomes, but the relationship between the various chromosome configurations and chiasma frequency is not clear cut. 

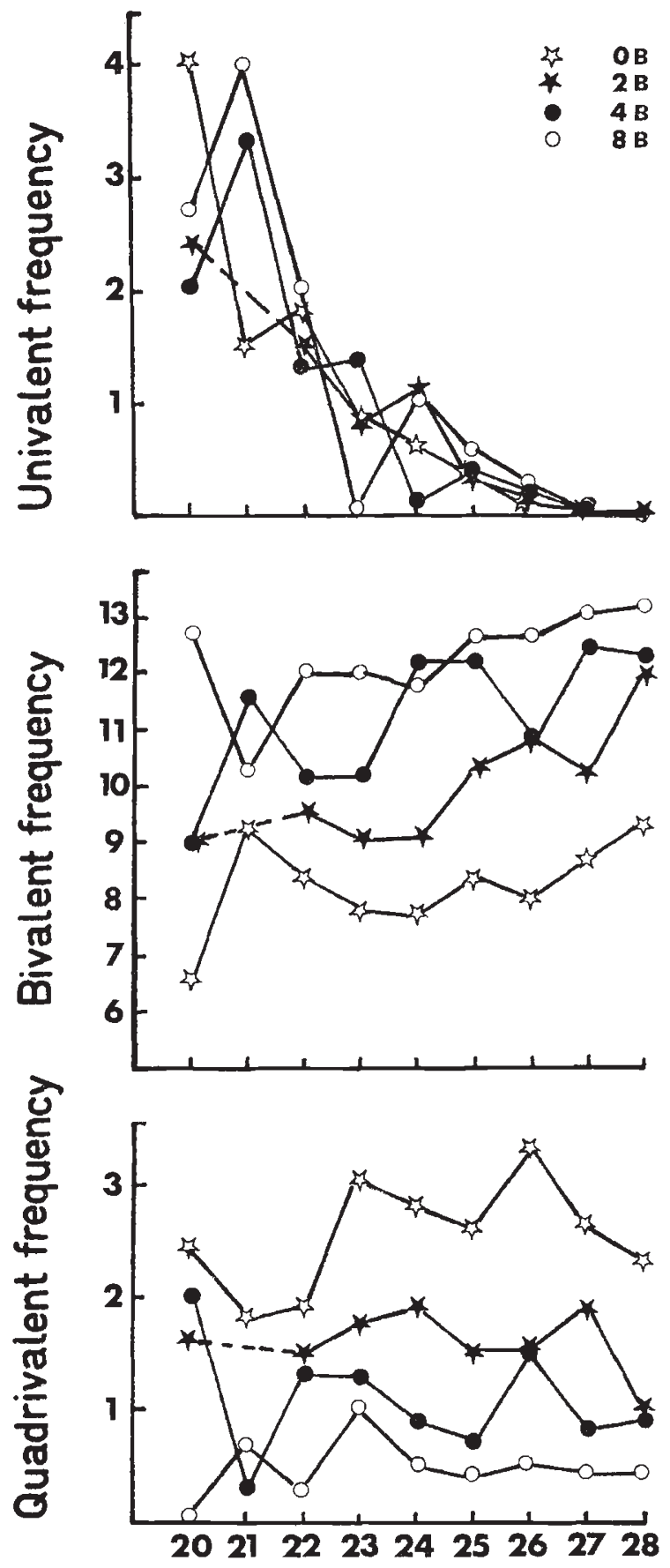

Cell chiasma frequency

Fig. 2.-Mean frequencies of univalents, bivalents and quadrivalents in cells with the same chiasma frequency for each B chromosome class. 
In figure 2 the mean number of univalents, bivalents and quadrivalents in cells with the same number of chiasmata have been plotted for each B chromosome class so that cells with the same number of chiasmata but different numbers of Bs can be compared. Quadrivalent frequency does not change with increasing chiasma frequency in any of the chromosome classes and the regressions are not significant. However bivalent frequency does appear to be related to chiasma frequency in the $2 \mathrm{~B}$ and $4 \mathrm{~B}$ chromosome classes. In the $2 \mathrm{~B}$ class the regression is significant at the 1 per cent level of probability and in the $4 \mathrm{~B}$ class it is significant at the 5 per cent level. The regressions are not significant in the $\mathrm{OB}$ and $8 \mathrm{~B}$ classes. In all $\mathrm{B}$ chromosome classes there is a significant decrease in the frequency of univalents with increasing chiasma frequency.

\section{Discussion}

In diploid hybrids between these two species there was a progressive decrease in chiasma frequency and bivalent frequency with increasing $\mathbf{B}$ chromosome number (Murray, 1976). This would suggest that B chromosomes bring about a reduction in homoeologous pairing at the diploid level. The results presented here would appear to support the idea that increasing $\mathrm{B}$ chromosome numbers also have a progressive effect on the level of homoeologous pairing at the tetraploid level. With high numbers of Bs the chromosomes show a very high degree of bivalent formation which is not in all cases related to chiasma frequency, so there must be a certain degree of redistribution of chiasmata. It would therefore appear that the Bs promote pairing between homologues and the greater the number of Bs in the cell the more effective is the promotion of homologous pairing. However it is possible, though unlikely in view of the effects of Bs on homoeologous pairing in the diploid hybrids, that the Bs are simply promoting bivalent formation per se. This possibility cannot be completely discounted since the chromosomes of both species are of similar size and bivalent formation between homologues cannot be distinguished from bivalent formation between homoeologues.

Accepting the most probable interpretation, that B chromosomes suppress homoeologous pairing in hybrids between species of Briza as well as in a number of grass genera, it is worth speculating why this should be. It is of vital importance for $\mathbf{B}$ chromosomes that they do not pair with the A chromosomes that they are derived from, since the formation of multivalents will have an adverse effect on fertility. If the Bs evolve loci that suppress $\mathrm{A} / \mathrm{B}$ pairing they may also act to suppress pairing of all homoeologues. This can be used to explain why different hybrid combinations are affected to different extents by $\mathrm{B}$ chromosomes. The gene locus or loci on the $\mathrm{B}$ chromosome would be less effective in reducing pairing between chromosomes of very closely related species since they will show a greater degree of homology than exists between the chromosomes of more distantly related species where Bs have a more pronounced effect (Evans and Macefield, 1973, 1974). The situation in Briza where there is a dosage effect would appear to show that pairing between very similar chromosomes can be reduced by increasing the number of pairing control loci as a result of increasing the number of $\mathbf{B}$ chromosomes. Although Taylor and Evans (1976) have shown that the A chromosome genotype can modify the effects 


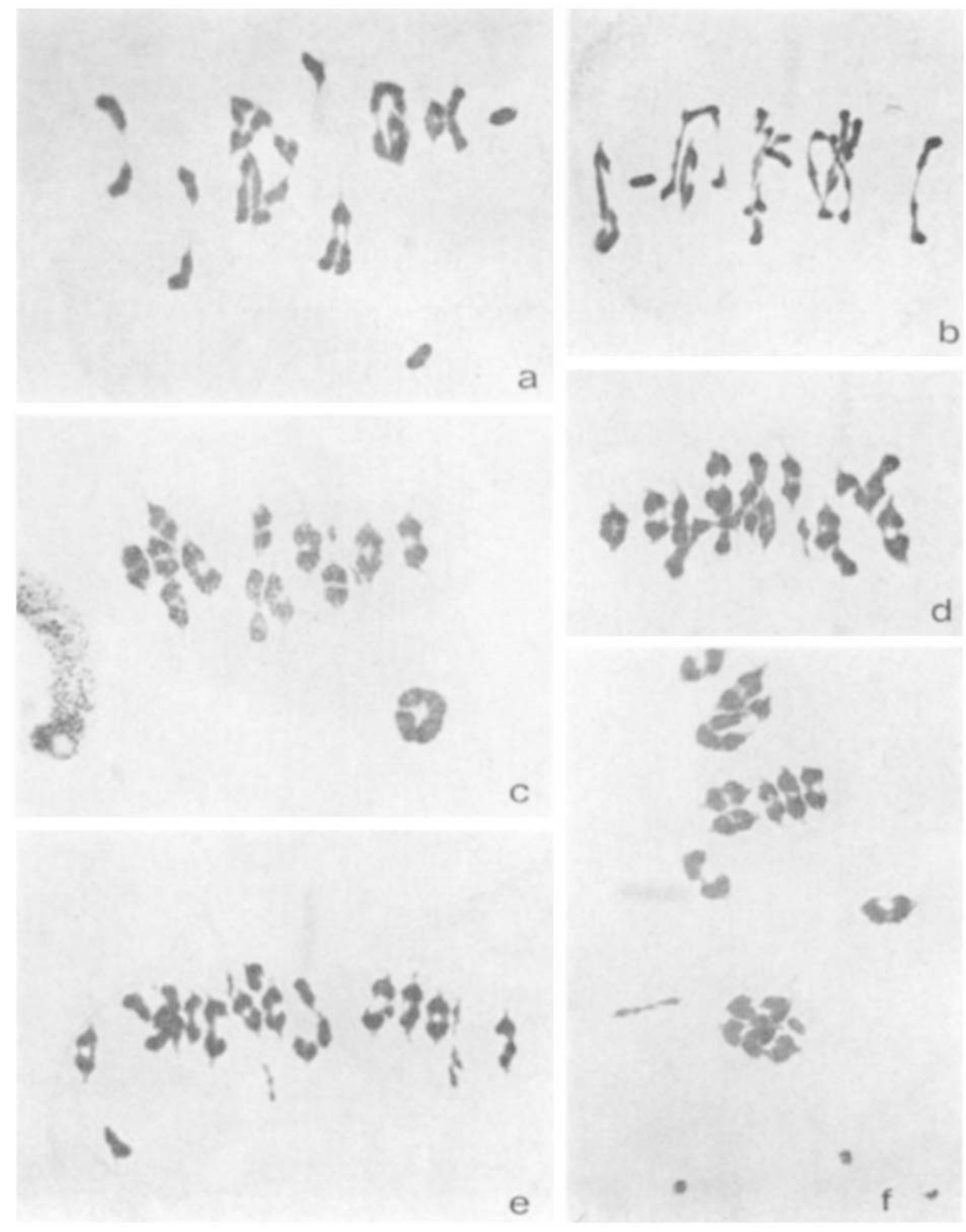

Plate I

Fic. 1.-Meiotic metaphase I in tetraploid hybrids between Briza media and Briza elatior. $a$ and $b$, cells from plants without $B$ chromosomes showing high frequencies of multivalent formation; $\mathrm{c}$ and d, cells from $2 \mathrm{~B}$ plants with one (c) or two (d) quadrivalents; $e$ and $\mathrm{f}$, cells from $8 \mathrm{~B}$ plants with very low quadrivalent frequencies and high bivalent frequencies. 
of Bs in species hybrids, this does not negate the hypothesis suggested above, since in all the families they studied the Bs always, though sometimes to a very small extent, suppress homoeologous pairing.

\section{REFERENCES}

EVANS, G. M., AND MACEFIELD, A. J. 1972. Suppression of homoeologous pairing by B chromosomes in a Lolium species hybrid. Nature Nerw Biol., 236, 110-111.

EVANS, G. M., AND MACEFIELD, A. J. 1973. The effect of B chromosomes on homoeologous pairing in species hybrids. I. Lolium temulentum $\times$ Lolium perenne. Chromosoma (Berl.), 41, 63-73.

EVANS, G. M., AND MACEFIELD, A. J. 1974. The effect of B chromosomes on homocologous pairing in species hybrids. II. Lolium multiflorum $\times$ Lolium perenne. Chromosoma (Berl.), $45,369-378$.

MURRAY, B. G. 1976. The cytology of the genus Briza L. (Gramineae). III. B chromosomes. Chromosoma (Berl.), 59, 73-81.

TAYLOR, I. B., AND EVANS, G. M. 1976. The effect of B chromosomes on homoeologous pairing in species hybrids. III. Intraspecific variation. Chromosoma (Berl.), 57, 25-32. 